\title{
DESASTRE, DESTRUIÇÃO, CRIAÇÃO: DO NADA ÀS CINZAS
}

\author{
Juan Manuel Terenzi* \\ Universidade Federal de Santa Catarina
}

\begin{abstract}
Resumo: Este artigo propõe discutir, de maneira sucinta, acerca do nada, do fogo, das cinzas e do poder de criação que deles deriva. Para levar a cabo esta discussão, inicialmente nos valeremos de alguns conceitos filosóficos abordados por Martin Heidegger. Em seguida, discutiremos a leitura efetuada por Jacques Derrida sobre o conceito de Geist (Espírito) em Heidegger. Derrida irá investigar o uso desta palavra e suas variantes ao longo da obra filosófica de Heidegger, identificando possíveis leituras que estariam ocultas e que descortinariam um teatro heideggeriano em torno desta palavra. A leitura do filósofo da desconstrução tece importantes considerações e permite ao leitor novas aproximações à obra heideggeriana. Com estes dois eixos definidos, elaboramos uma leitura que põe de manifesto a relação entre os seguintes conceitos: o nada, o fogo e as cinzas, relacionados com o ato de criação. Ao longo do artigo destacamos outros escritores e filósofos, tais como Heráclito, Habermas, Wittgenstein e Beckett.
\end{abstract}

Palavras-chave: Heidegger. Derrida. Fogo. Nada. Criação.

Le soleil brillait, n'ayant pas d'alternative, sur le rien de neuf.

Samuel Beckett

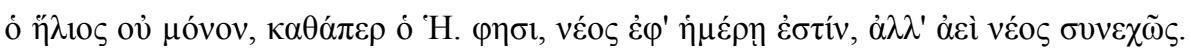
[O Sol não apenas é novo a cada dia, mas sempre e continuamente.]

Heráclito

Diante de todos os acontecimentos que abalam o mundo atual, parece inevitável o caráter de destruição - entendida em sua gama plural de significados - que configura este cenário e se apodera do cotidiano. Destruição não apenas física dos entes que habitam o mundo, mas igualmente destruição da relação moral, da comunidade, dos vínculos entre os seres humanos, e destes para com o seu entorno, seja este humano ou não (vide os recursos naturais, por exemplo). Portanto, estamos diante de um novo questionamento, que nunca deixou de estar presente nas especulações filosóficas, literárias e científicas dos homens de

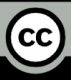

BY Esta obra está licenciada sob uma Creative Commons - Atribuição 4.0

\footnotetext{
* Graduado em Engenharia Química pela Universidade Federal de Santa Catarina - UFSC (2007), em licenciatura e bacharelado no Curso de Letras-Espanhol - UFSC (2011). Mestre em Literatura (2014). Pesquisador do Núcleo Juan Carlos Onetti de Estudos Literários Latino-Americanos - UFSC. Atualmente é doutorando no Programa de Pós-Graduação em Literatura $(\mathrm{CNPq})$ orientado pela professora Dra. Liliana Reales. E-mail: <jmterenzi@hotmail.com>.
} 
espírito crítico. Ou seja, novamente nos enfrentamos com o avassalador surgimento do nada, do mais fundo dos fundamentos, o qual habita os abismos e que não deixa de afundar. $\mathrm{O}$ próprio Heidegger, no Posfácio ao ensaio “Que é Metafísica?” tece esta consideração: “A metafísica se move, em toda parte, no âmbito da verdade do ser que lhe permanece o fundamento desconhecido e infundado". (HEIDEGGER, 1979, p. 47).

Desde Hesíodo, passando pelo pensamento cristão, e chegando até nós, a origem do cosmo mantém-se oculta. Afinal, esta é a questão cujo fundamento desconhecemos, mas cuja dignidade mantem-se a mais alta. Com esta introdução não queremos vincular os conceitos de nada e destruição, embora entre estes haja uma intimidade que insiste em ser desconhecida para nós. Igualmente, trata-se de uma questão que concerne ao espírito, e para isto analisaremos, posteriormente, a leitura que Derrida efetua de alguns termos que giram em torno da palavra Geist, utilizada por Heidegger em alguns de seus escritos. Comecemos, então, com o nada.

Heidegger afirmara que o Nada - aqui entendido na sua acepção com maiúscula configura-se como a "primeira de todas as questões" (HEIDEGGER, 1978, p. 33), vindo a elaborar uma longa argumentação acerca do nada em “Que é Metafísica?”, verificando que a ciência o rejeita, mas que a filosofia deve discorrer sobre a sua posição enigmática. $\mathrm{O}$ pensador da floresta negra posiciona este nada antes mesmo da negação lógica, pois esta só existe através do nada mais originário: "Nós afirmamos: o nada é mais originário que o "não" e a negação.” (HEIDEGGER, 1978, p. 37). Heidegger problematiza e indaga sobre o império da lógica, a questão que se faz é muito mais profunda, seu fundo mesmo é desconhecido. Entretanto, se pensar é sofrer, permaneçamos na dor ao invés de nos conformarmos com a leitura feliz da vida. Afinal, para citarmos alguns nomes que de certa maneira lidaram e efetuaram a destruição da Filosofia, podemos citar desde Nietzsche e seu martelo, passando por filósofos mais contemporâneos como Wittgenstein, Heidegger e Derrida, estes dois últimos objetos do presente trabalho. Por sua vez, no campo da literatura, um dos que mais se debruçou e enfrentou o espanto do abismo foi Samuel Beckett, que da mesma forma que Wittgenstein amparou-se fortemente no jogo de xadrez para fornecer-lhe material de escrita. ${ }^{1}$

\footnotetext{
1 Se para o filósofo vienês o jogo de xadrez (Schachspiel) é recorrente ao discutir os jogos de linguagem (Sprachspiel), a semelhança de família, a noção de seguir regras, a linguagem como uso, entre outros conceitos elaborados nas Investigações Filosóficas, o escritor irlandês escreve uma peça cujo título é uma alusão a uma das etapas do jogo, Fin de partie (Endgame), além de uma novela Murphy, que alguns críticos interpretam como uma alusão ao jogador estadunidense Paul Morphy. Inclusive, em Murphy há uma partida anotada - por sinal, absurda de ser jogada, pois são lances extremamente inverossímeis em uma partida disputada por dois jogadores que saberiam jogar, ao menos, em um nível iniciante. Contudo, o que queremos deixar claro é a importância que o xadrez exerce nestes dois pensadores, um jogo de forte caráter bélico, mas que conserva também uma beleza
} 
Dizemos isto, pois podemos pensar a relação que há entre o xadrez, a destruição e a criação. Ao jogarmos, enfrentamos um adversário, o qual queremos vencer - excetuando casos em que um empate pode ser acordado entre ambas as partes - caracterizando um aspecto destrutivo no tabuleiro, mas ao mesmo tempo, criam-se jogadas, além de outras tantas variantes que ocorrem apenas em potência e que não se realizam concretamente no jogo, como é o caso quando um jogador pondera sobre qual lance realizar antes de efetuar o lance com sua mão. Veja como a mão é importante no jogo, pois a partir do momento em que se toca a peça não há a possibilidade de retornar ou anular o lance, toucher jouer! é uma das regras do jogo. Enfim, este excurso serve para adentrar no âmbito do nada, trazendo para o debate um detalhe que poderia passar despercebido - o xadrez - e como pode-se associá-lo ao enfrentamento com o vazio, o sem sentido, o nada que nos assombra. A questão que guia toda a discussão de Heidegger não é uma questão qualquer, obviamente. Conduzi-la assemelha-se a entrar numa floresta sem nenhum mapa, viajar num barco mar adentro sem nenhuma bússola. Erramos, no sentido etimológico que a palavra nos oferece. Eis o que nos diz Heidegger: "O nada é a plena negação da totalidade do ente.” (HEIDEGGER, 1978, p. 38). O filósofo prossegue sua especulação, interrogando acerca dessa totalidade do ente, como seria possível abarcá-la e experienciá-la. É aqui que entra em cena o tédio e a angústia. Por um lado, o tédio profundo que “como névoa silenciosa desliza para cá e para lá nos abismos da existência, nivela todas as coisas, os homens e a gente mesmo com elas, numa estranha indiferença. Este tédio manifesta o ente em sua totalidade." (HEIDEGGER, 1978, p. 38). Porém, para que possamos entrar em contato com o nada originário, outra tonalidade afetiva (Stimmung) deve fazer-se presente. Trata-se da angústia, pois é ela que, de acordo com Heidegger, manifesta o nada. $\mathrm{O}$ nada, por sua vez, representaria a liberdade radical do ser, já que "Sem a originária revelação do nada não há ser-si-mesmo, nem liberdade.” (HEIDEGGER, 1978, p. 41). Interessante notar que há uma oscilação entre a totalidade e o nada, pelo fato de que a presença de um aniquila o outro. Esta contradição também marcara o escritor irlandês que citamos anteriormente, quando ele discute as suas possibilidades de continuar escrevendo em inglês - sem esquecermos que Beckett é posterior a James Joyce, grande revolucionário da língua inglesa: "E, mais e mais, minha própria língua me parece como um véu que precisa ser rasgado para chegar às coisas (ou ao Nada) por trás dele.” (apud ANDRADE, 2001, p. 169).

Neste pêndulo entre as coisas e o nada oscila a nossa existência. Ou, empregando o vocabulário das tonalidades afetivas em Heidegger, entre o tédio profundo e a angústia. dialogam. 
Entretanto, não devemos considerá-los como meros opostos, entendendo que o nada é aquilo que possibilita a revelação do ente, seguindo a esfera especulativa do filósofo alemão ${ }^{2}$. De fato, as ciências exatas também se deparam com o nada quando buscam orientar as suas pesquisas na direção daquilo que seria o começo do universo, da explosão inicial, de um ponto extremamente denso que continha em si a totalidade da matéria No entanto, por mais que se colidam prótons, ou o que quer que seja, no acelerador de partículas localizado na Suíça, ainda estaremos distantes desse nada primordial que permanece enigmático, e que justamente por esta característica, impulsiona as nossas atividades diárias. Mas, como dissemos antes, pelo pensar temos acesso também ao sofrimento, ao fragmentário, revelando nosso distanciamento com o todo e o Uno, tão desprezado na pós-modernidade. Dizer que há o Um ou que o Todo pode ser acessado soaria ofensivo aos ouvidos de alguns, mas o escopo da Filosofia nunca pode abandonar a pretensão do todo, caso contrário, seria apenas uma ramificação, um fragmento solitário que nada pretenderia, exceto a sua falível posição soberana. Porém, tampouco devemos nos enganar a nosso respeito, pois Heidegger nos recorda, por meio de Nietzsche, o lugar e o tempo que ocupamos no universo:

Em sua superfície vive, rastejando em profusão um punhado entorpecido de animais
pretensamente astutos, que por um instante descobriram o conhecimento (Cfr.
Nietzsche, Sôbre a Verdade e a Mentira no sentido extra-moral, 1873 inédito). E o
que significa o espaço de tempo de uma vida humana no curso de milhões de anos?
Mal uma pulsação do ponteiro de segundos, um sôpro de respiração. Dentro da
totalidade do ente não há razão para se privilegiar este ente, que se chama homem e
ao qual pertencemos por acaso. (HEIDEGGER, 1978, p. 35).

Logo, o nosso questionar, a procura pelo por que, por algo que fundamente decisivamente toda a nossa cadeia de pensamentos, torna-se frágil. Heidegger mesmo, denomina esta atividade da filosofia de loucura, ou melhor, a questão que ele propôs, consiste em uma loucura para a fé.

Após falarmos do nada, discutamos acerca do fogo, das cinzas e do espírito. Todos estes conceitos estão atrelados de alguma forma com esse nada originário heideggeriano. Afinal, a questão de Heidegger indaga igualmente acerca do fogo, desse elemento que consome em si todas as coisas, deixando delas apenas traços, cinzas, para utilizarmos o vocabulário derrideano. Antes de mergulharmos na filosofia de Derrida e na sua leitura de Heidegger, a qual podemos ver em De l'esprit. Heidegger et la question, convém refletir um pouco acerca destes conceitos trabalhados já nos tempos antigos. Se retornarmos aos

\footnotetext{
${ }^{2}$ Nas palavras de Heidegger: "O nada é a possibilidade da revelação do ente enquanto tal para o ser-aí humano. O nada não é um conceito oposto ao ente, mas pertence originariamente à essência mesma (do ser). No ser do ente acontece o nadificar do nada.”. (HEIDEGGER, 1978, p. 41).
} 
pensadores da Antiguidade, veremos que alguns deles desenvolvem alguns argumentos dignos de consideração sobre o fogo. Escolhemos dois fragmentos de Heráclito para iniciarmos este caminho pelo ardor do fogo. No fragmento 14 lê-se:

[¿Para quiénes precisamente profetiza Heráclito de Éfeso?] Para hechiceros nocturnos, magos, bacantes, ménades, iniciados; [a éstos amenaza con lo que está después de la muerte, a ellos profetiza el fuego (toútois manteúetai tò pýr)]. Pues los que se consideran misterios entre los hombres son celebraciones sacrílegas. (PRESOCRÁTICOS, 2008, p. 187).

Por sua vez, o fragmento 30 é mais direto em revelar a relação do universo e do fogo: "A este mundo, el mismo de todos, no lo hizo ni uno de los dioses ni uno de los hombres, sino que siempre era, es y será fuego siempre viviente (ên aeì kaì éstin kaì éstai pýr aeízoon), que se enciende según medida y se extingue según medida.” (PRESOCRÁTICOS, 2008, p. 201).

Portanto, nestes dois fragmentos de um dos filósofos mais estimados por Heidegger, ressoa o ruído do fogo e suas labaredas tocam nosso pensamento. Fogo e destruição, fogo e criação, fogo e tudo, fogo e nada. Um fogo sempre vivente - aeízoon. Ao longo dos fragmentos de Heráclito, o fogo (pýr) exerce uma função dominante e conduz o seu pensamento. Lembremos que a biblioteca de Alexandria, casa do saber durante séculos, fora incendiada. Livros queimaram, o papel incendiou-se e boa parte de nossos conhecimentos desenvolvidos até então extinguiu-se nas chamas. Entretanto, o mesmo fogo que destruiu pode ser pensado como metáfora para descrever o que ocorre no pensamento. Wittgenstein, em Zettel (1967), dedica três parágrafos $(\S 125, \S 126, \S 127)$ para associar a atividade mental com a atividade do fogo. No primeiro, ele nos convida, por meio de uma exclamação, a associar dois fenômenos: o pensar e o queimar (Phänomen des Denkens mit dem Phänomen des Brennens!). Ambos possuiriam um mistério, um enigma (Rätsel) para Wittgenstein, deixando em suspenso como resolver o enigma do pensamento: deveríamos solucioná-lo como aquele da chama? (Und wie sol nun das Rätsel des Denkens aufgelöst werden? - Wie das der Flamme?). No parágrafo seguinte, ele considera o fato de que a chama é impalpável, fazendo com que ela se torne misteriosa, e que nosso desejo é agarrar as coisas, torna-las palpáveis. (Außer, weil wir es greifen wollen). Finalmente, no parágrafo §127, aparece a palavra Geist, cara à discussão que se desenvolveu ao longo do curso. Esta aparição encontra ecos na conceitualização wittgensteiniana do uso de uma palavra: "Zeige mir, wie du das Wort "seelisch" gebrauchst, und ich werde sehen, ob die Seele "unkörperlich" ist, und was du unter "Geist" verstehst." (WITTGENSTEIN, 1967, p. 23)

Selecionamos estes três parágrafos de Wittgenstein apenas com o intuito de demonstrar que o fogo não só amparou, mas ainda mantém acesa a chama do pensamento em 
várias etapas da Filosofia. Se nestes dois pensadores, distanciados cronologicamente em mais de 24 séculos, o fogo e suas chamas vieram em auxílio, isto mostra que nele há uma força que hipnotiza. Com base nesta potência das chamas, entraremos na lareira de Derrida ${ }^{3}$, em sua leitura de alguns usos da palavra Geist e seus derivados em diversos momentos da obra de Heidegger. As palavras iniciais do livro anunciam o que está por vir: "Je parlerai du revenant, de la flamme et des cendres." (DERRIDA, 1987, p. 11).

Serão estas três palavras que irão guiar a conferência proferida por Derrida no dia 14 de março de 1987. Palavras evitadas por Heidegger - vermeiden ${ }^{4}$. Antes de aprofundar nesta análise, é importante destacar que Derrida é um filósofo que seguindo as trilhas abertas por Heidegger, no que concerne ao método de destruição da metafísica discutida no $§ 6$ de Sein und Zeit, cunhou seu próprio pensamento de desconstrução. O ataque é dirigido a toda pretensão da filosofia de fundamentar sua atividade na fala, no logos: "A fórmula derridadiana, como veremos, resume-se assim: logocentrismo = fonocentrismo, ou então: ontologia = otologia." (HEBECHE, 2006, p. 3). O grande inimigo de Derrida é a filosofia desenvolvida por Platão e levada adiante por seus seguidores. Na concepção desconstrutiva, opera-se outra leitura da Antiguidade: “[...] Derrida, partindo de Saussure, faz uma outra leitura dos filósofos gregos: não é a imagem ou a representação visual, mas a representação sonora a fonte do logocentrismo." (HEBECHE, 2006, p. 8). Todavia, seu método não esteve isento de objeções, uma vez que se valia da Literatura e da Linguística para dar conta da sua tarefa de desconstruir tudo que tinha sido edificado na tradição metafísica. Habermas discute criticamente esta via dupla trilhada por Derrida - poesia e filosofia - "Na práxis desconstrutiva prova-se a fragilidade da diferença de gênero entre filosofia e literatura" (HABERMAS, 2000, p. 267), dois campos do saber trilhados desde os pré-socráticos, inclusive alguns deles, como Empédocles, Parmênides e Xenófanes, utilizavam-se da métrica para escrever. Eis uma das inúmeras críticas de do filósofo de Düsseldorf em seu excurso:

Derrida procede antes à maneira da crítica estilística, extraindo o excedente retórico de significado das camadas literárias de um texto que se apresenta como nãoliterário, algo como mensagens indiretas com as quais o próprio texto desmente os

\footnotetext{
${ }^{3}$ Sobre o aconchego junto ao fogo e os debates que ele proporciona, vale a pena recordar um fragmento de Xenófanes, cuja beleza estética e profundidade manifestada pelas questões levantadas, ilustra o que aqui se desenvolve: "Junto al fuego conviene decir estas cosas, en la estación invernal, mientras uno está reclinado en un blando lecho, satisfecho, bebiendo dulce vino y comiendo garbanzos; “¿Quién eres tú entre los hombres? ¿De dónde vienes? ¿Cuántos años tenías cuando llegó el medo?” (JENÓFANES, 2008, p. 137). Atualmente, os curdos dizem ser os descendentes dos medos. Espirituosamente, podemos associar este povo com a palavra "medo" em português, gerando uma pergunta peculiar: Quantos anos você tinha quando chegou o medo? Pergunta não destituída de fundamento, uma vez que os medos eram tidos por um povo de potencial bélico elevado.

${ }^{4}$ De acordo com Derrida: "Et de ce que, pour Heidegger, éviter veut dire.” (DERRIDA, 1987, p. 11).
} 
seus conteúdos manifestos. Dessa maneira, Derrida forças os textos de Husserl, de Saussure ou de Rousseau a depor contra a opinião explícita dos seus autores. (HABERMAS, 2000, p. 267)

Ironicamente, Habermas denuncia a mudança do jargão levada a cabo por Derrida em relação a Heidegger: "De início imperceptível, a metamorfose da "destruição" da tradição filosófica em "desconstrução" transfere a crítica radical da razão para o domínio da retórica [...]" (HABERMAS, 2000, p. 267). O debate demandaria um tempo superior ao aqui permitido, mas fica aqui exposta a crítica ao método - ou melhor, a errância ${ }^{5}$ - utilizado por Derrida.

Seguindo a crítica aberta por Nietzsche, a qual também se valia de notórias características literárias, a discussão de Derrida não se preocupa em revelar uma única verdade, um ponto fixo que daria sentido a todos os demais através de deduções lógicas e racionais. Derrida defende o pensamento do traço, da arqui-escritura, de um signo diferente do proposto até então pelos esforços dos pensadores. Entretanto, tal empreendimento não se mostra fácil, pois como bem observa Hebeche: "Todos os discursos destruidores da metafísica fazem um "círculo", pois dependem daquilo que pretendem destruir, alimentam-se dele, pois foi com os conceitos herdados da metafísica que Nietzsche, Heidegger e Freud operaram [...]” (HEBECHE, 2006, p. 11). Os filósofos aqui levantados pertencem à linhagem dos destruidores, e aos quais poder-se-iam somar igualmente Wittgenstein e Heráclito, para retomarmos estes dois filósofos separados por um lastro temporal gigantesco. Transcrevamos outros fragmento de Heráclito, o de número 66: “[En efecto, dice,] el fuego (tò pýr), después de venir sobre todas las cosas (pánta), las juzgará (krínei) y condenará (lépsetai).” (PRESOCRÁTICOS, 2008, p. 235). Novamente o fogo e a destruição. Mas, afinal de contas, o que é que eles destroem? Trata-se, no fundo, de afundar a pergunta cada vez mais em seu abismo, de não resgatá-la artificiosamente, com a pretensão de dominá-la. Nietzsche, Heidegger, Wittgenstein, Derrida, e ainda Heráclito, são questionadores do fogo que destrói e cria cinzas. Filosofia das cinzas, filosofia do defunto ${ }^{6}$.

Voltando a Derrida e à sua afirmação de que aquilo de que ele falará concentra-se na aparição, no fogo e nas cinzas, percebe-se que $h a ́ a i^{7}$ destruição, pois para obtermos cinzas

\footnotetext{
5 Se a palavra método conserva em si a palavra grega hodós, Derrida permanece na errância de sua desconstrução, que ressoa na palavra différance.

${ }^{6}$ Numa bela passagem de Feu la cendre, lemos: "Non, la frase ne dit pas ce qu'elle est, mais ce qu'elle fut, et comme ce vocable fut employé par vous déjà tant de fois depuis tout à l'heure, n'oubliez pas qu'il reste en mémoire de feu, du mot feu dans l'expression feu un tel ou feu une telle. Cendre de toutes nos étymologies perdues, fatum, fuit, funcuts, defunctus." (DERRIDA, 2009, p. 21).

${ }^{7}$ Em 1987, no mesmo ano que Derrida profere sua conferência, é lançado o livro Feu la cendre, que entre outras coisas discutirá a oração Il y a là cendre, em que o acento em "a" pode ser apenas lido e não ouvido, causando
} 
algo deve ser queimado, algo deve ser lançado ao fogo. O holocausto far-se-á presente no discurso, os corpos mortos da segunda guerra, os espectros de mais de 30 anos atrás. $\mathrm{O}$ filósofo argelino lembra-nos que o espírito não é nem uma palavra de destaque na filosofia heideggeriana, nem nos seus comentaristas ${ }^{8}$ : “[...] l'esprit, voilà du moins l'apparence, ce n'est pas un grand mot de Heidegger. [...] Personne ne parle jamais de l'esprit chez Heidegger." (DERRIDA, 1987, p. 15-16). O discurso de Derrida muitas vezes nos escapa, mas percebe-se uma crítica pesada a Heidegger em determinados momentos, sobretudo quando aparece a noção do Führer e de Geschlecht - palavra que Derrida aponta como sendo de difícil tradução. Derrida identifica no discurso de Heidegger, quando assume a Reitoria em 1933, a inflamação do espírito. Le Geist est flamme. A autoafirmação de que o Espírito é chama está presente neste discurso, cujas palavras conservam uma ambiguidade inevitável. Inclusive o próprio desenrolar do texto de Derrida torna-se complexo, emaranhado de referências e subtextos. Porém, do último parágrafo do quinto capítulo podemos extrair algumas palavras que acompanham o que desejamos expor aqui:

Mais la géopolitique nous reconduit encore de la terre et de la planète au monde et au monde comme monde de l'esprit. La géopolitique n'est autre qu'une Welpolitik de l'esprit. Le monde n'est pas la terre. Sur la terre advient un obscurcissement du monde (Weltverdüsterung): la fuite des dieux, la destruction de la terre, la massification des hommes, la prééminence du médiocre. (DERRIDA, 1987, p. 73)

Finalmente, tudo se transforma em cinzas, o fogo de Heráclito ainda hoje se faz sentir, flamejando. Nas últimas palavras de Derrida, ouvimos ressoar novamente as três palavras, como um longínquo aceno bíblico, como o resto da dialética hegeliana, cuja síntese são as cinzas. Cinza síntese: "L'esprit qui veille en revenant fera toujours le reste. A travers la flamme ou les cendres, mais comme le tout autre, inévitablement." (DERRIDA, 1987, p. 184). Uma vez acesa a fogueira, as cinzas tomam o lugar da palavra.

Heidegger, 20 anos após ter escrito “Que é Metafísica?”, ou seja, imerso no clima de destruição após os estragos causados pela segunda guerra, escreve que a questão levantada por Leibniz, "Pourquoi il y a plutôt quelque chose que rien?”, que encontra eco nas epígrafes, aparentemente contraditórias, que selecionamos, pois esse nada de novo (rien de neuf) narrado por Beckett, o qual retoma os versos presentes no Eclesiastes ${ }^{9}$, vincula-se tragicamente aos entes iluminados pelo Sol - o sol brilhava (le soleil brillait), - essa aparente

essa ambiguidade que deleita Derrida. Pois a frase pode ser ouvida tanto como "Há aí (là) cinza" como "Há cinza (la cendre)"

${ }^{8}$ No final do segundo capítulo, Derrida ensaia uma definição de Geist: “Geist est peut-être le nom que Heidegger donne, au-delà de tout autre nom, à cette possibilite inquestionée de la question." (DERRIDA, 1987, p. 26).

9 "Nihil sub sole novum". Versão latina da Bíblia (Vulgata), 1:9. 
repetição dos dias, contraposta ao Sol sempre novo de Heráclito, conserva em si uma simplicidade enigmática que Leibniz elucida: "Car le rien est plus simple et plus facile que quelque chose."

\section{Agradecimentos:}

Ao professor e escritor Luiz Alberto Hebeche.

\section{Referências}

ANDRADE, Fábio de Souza. Samuel Beckett: o silêncio possível. Cotia: Ateliê Editorial, 2001.

DERRIDA, Jacques. De l'esprit. Heidegger et la question. Paris: Galilée, 1987.

La difunta ceniza [Feu la cendre - 1987]. Trad. de Daniel Álvaro y Cristina de Peretti. Buenos Aires: La Cebra, 2009.

HABERMAS, Jürgen. $O$ discurso filosófico da modernidade. Trad. de Luiz Sérgio Repa Rodnei Nascimento. São Paulo: Martins Fontes, 2000.

HEBECHE, Luiz. Considerações sobre Derrida. Florianópolis: EdUFSC, 2006.

HEIDEGGER, Martin. Introdução à Metafisica. Trad. e notas de Emanuel Carneiro Leão. Rio de Janeiro: Tempo Brasileiro, 1978.

. “O que é Metafísica”. Trad. de Ernildo Stein. São Paulo: Abril Cultural, 1979.

PRESOCRÁTICOS. Fragmentos I. Introd., trad. e notas de Ramón Cornavaca. Buenos Aires: Losada, 2008.

WITTGENSTEIN, Ludwig. Zettel. Los Angeles: California University Press, 1967.

[Recebido em janeiro de 2016 e aceito para publicação em abril de 2016]

\section{Desaster, destruction, creation: from nothing to ashes}

Abstract: The aim of this article is to briefly discuss about certain notions as nothing, fire, ashes and the creative power that derives from them. To reach this aim, first of all we chose some philosophical concepts extracted from Heidegger's philosophy. Then, we are going to discuss the book De l'esprit: Heidegger et la question from Jacques Derrida, in which he pays attention to the use of the word Geist (mind/spirit). Derrida will investigate the use of this word and its variants in Heidegger's philosophical work, identifying potential readings that could be hidden, uncovering a huge heideggerian theatrical scenery around this word. The philosopher of deconstruction's reading makes important contributions and allows the reader new approaches to Heidegger's philosophy. This two axes will aid our own reading in order 
to show the relation between those notions: nothing, fire, ashes, related to creative act. In this article other names will also appear, as Heraclitus, Habermas, Wittgenstein and Beckett.

Keywords: Heidegger. Derrida. Fire. Nothing. Creation.

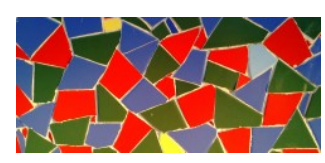

